\title{
Erratum to: The new biology of diabetes
}

\author{
Utpal B. Pajvani ${ }^{1} \cdot$ Domenico Accili $^{1}$
}

Published online: 17 September 2015

(C) Springer-Verlag Berlin Heidelberg 2015

\section{Erratum to: Diabetologia}

DOI 10.1007/s00125-015-3722-5

Unfortunately the meaning of a sentence in the section on 'FOXO and hormone regulation of gene expression' was altered during editing. The sentence 'Thus, FOXO integrate energy intake with energy expenditure in the central nervous system through regulation of neuropeptide processing and signalling [27-29], in liver through glucose and lipid production $[17,30]$, in adipocytes through NEFA turnover [31] and in the vasculature through nitric oxide production and inflammatory responses $[32,33]$.' should have read 'Thus, in the central nervous system FOXO integrate energy intake with energy expenditure through their actions on neuropeptide production, processing and signalling [27-29]. In liver, FOXO regulate hepatic glucose and lipid production $[17,30]$, and in adipocytes, NEFA turnover [31]. In the vasculature, they regulate nitric oxide production and inflammatory responses $[32,33]$.

The online version of the original article can be found at http://dx.doi.org/ 10.1007/s00125-015-3722-5.

Utpal B. Pajvani

up2104@columbia.edu

$\triangle$ Domenico Accili

da230@columbia.edu

1 Department of Medicine and Naomi Berrie Diabetes Center, Columbia University Medical Center, 1150 St Nicholas Av., New York, NY 10032, USA 